\title{
Safe surgical approach to extrahepatic pseudocyst, a rare shunt complication: 2 case reports
}

\author{
Gokhan Canaz ${ }^{1 *}$, Erhan Emel', Serhat Baydin², Suat Can Ulukent ${ }^{3}$, Yaser Ozgunduz $^{1}$ and Orhun Mete Cevik ${ }^{1}$
}

\begin{abstract}
Background: Hepatic pseudocysts are not a common complication and "extrahepatic" pseudocysts are rarer complications but may occur in every ventriculo-peritoneal shunt patient.

Case presentation: We present two patients with ventriculo peritoneal shunt induced extrahepatic pseudocysts, who underwent shunt surgery for different etiologies. Etiology, treatment strategies and our choice of treatment have been discussed.

Conclusions: When a ventriculoperitoneal shunt patient is presented with non-specific abdominal symptoms, the possibility of this complication should always be considered. In the treatment of this complication, it is shown that repositioning the catheter is sufficient for cyst regression.
\end{abstract}

Keywords: Ventriculo peritoneal shunt, Hydrocephalus, Hepatic, Pseudocyst

\section{Background}

The treatment of hydrocephalus is based on diverting cerebrso spinal fluid (CSF) into different body cavities; and peritoneum is still the most reliable and the most used place. The ventriculoperitoneal (VP) shunt-induced abdominal pseudocyst is a rare complication in patients with VP shunt which was first described by Harsh in 1954 [1]. Intestinal obstruction, intestinal perforation, peritonitis, abscess, bladder perforation and pseudocyst are the main abdominal complications of VP shunts. Pseudocyst occurence rates are reported to be between 1 and $3 \%$, and there are only limited number of cases of VP shunt-induced hepatic pseudocyts in the literature $[2,3]$. We report two cases of VP shunt induced extrahepatic pseudocyst patients with different backgrounds.

\section{Case presentation}

Case 1

Twenty-five years old female patient, who underwent a VP shunt implantation for hydrocephalus caused by meningitis at the age of 2 , applied to our clinic with pain

\footnotetext{
* Correspondence: gokhancanaz@gmail.com

${ }^{1}$ Bakirkoy Research and Training Hospital for Neurology, Neurosurgery and Psychiatry, Department of Neurosurgery, 34147 Bakırkoy/Istanbul, Turkey Full list of author information is available at the end of the article
}

along the shunt trace, nausea and abdominal pain. She had a revision surgery for shunt disfunction 3 years ago. Cranial computer tomography (CT) scan revealed no ventricular dilatation. Blood runs showed a mild elevation in the liver enzymes; sedimentation and CRP values were both in normal range. Radiographical studies showed that the shunt system was intact. Patient described pain in the upper right quadrant, and abdominal CT revealed subcapsular, extrahepatic $105 \times 85 \times 81 \mathrm{~mm}^{3}$ sized pseudocyst with the abdominal shunt catheter inside (Fig. 1). Surgery was planned. After surgical exploration with laparoscopic approach, the catheter slowly pulled back from cyst. The catheter was moved out easily. Cyst fluid was lucid, compatible with CSF. The abdominal catheter was directed to the Douglas pouch with the help of the laparoscope. No further intervention was made for the pseudocyst. Post-operatively, patients complaints were regressed. CSF cultures revealed that the cyst fluid was sterile. Follow ups showed that the pseudocyst was spontaneously resorbed.

\section{Case 2}

Thirty-four years old female patient admitted to our clinic with symptoms of nausea, blurred vision, and abdominal pain. She had undergone VP shunt implantation 

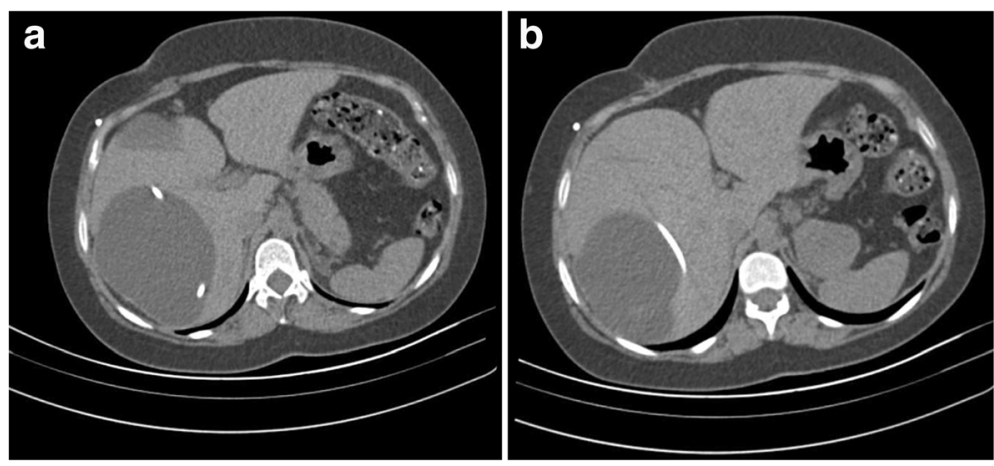

Fig. 1 a Subcapsuler, extrahepatic $105 \times 85 \times 81 \mathrm{~mm}^{3}$ sized pseudocyst in CT scan. Ingredient is isodense with CSF and abdominal shunt catheter is visible inside. $\mathbf{b}$ Folllowing axial section

for normal pressure hydrocephalus diagnosis in 2008, since then she had 3 revision operations for abdominal catheter dysfunctions in 2009, 2012 and 2016. Ultrasonographical study (USG) showed hepatic cystic mass measuring approximately $7 \times 5 \times 5 \mathrm{~cm}^{3}$. Abdominal CT revealed, $77 \times 47 \times 51 \mathrm{~mm}^{3}$ sized subcapsuler cystic mass with smooth margins with the abdominal shunt catheter inside (Fig. 2). Cranial CT showed mild ventricular dilatation. She had elevated CRP and sedimentation values. Hepatic enzymes were normal. In the operation, old abdominal incision was used and layers were passed. The catheter and the abdominal entry zone were found. The catheter was pulled out slightly and no adhesion encountered. We saw the catheter was working. The catheter was sent into the abdomen with a more upright angle to the lower quadrant. Post-operatively the complaints of the patient regressed and in the following one week the radiological studies showed that cyst were resorbed spontaneously (Fig. 3). CSF cultures revealed that the cyst fluid was sterile.

Case 1 had been followed up for 9 months, and case 2 had been followed up for 6 months, until the article reported, and no occurance of cyts' were observed during that time.

\section{Discussion and conclusions}

Abdominal pseudocysts are a rare VP shunt complication. It is characterized with a cystic mass encircled with a fibrous wall with CSF and the shunt catheter inside [4]. One of the theories about the abdominal pseudocyst etiology is the inflammation theory, which proposes the main reason as recurrent infections, shunt revisions, intestinal adhesions and peritonitis [5]. Furthermore, it is suggested that the allergic reactions and CSF oncotic pressure elevation due to high protein levels may help pseudocyst formations. Hepatic pseudocyst secondary to a VP shunt is a rarely a reported complication $[3,6]$. During the abdominal catheter implantation, damaging Glisson's capsule with shunt can cause subhepatic extrahepatic pseudocysts. Similarly, penetrating hepatic parenchyma with the shunt catheter can cause intra hepatic pseudocyts [7].

The most common symptoms caused by abdominal pseudocyst are abdominal pain (63\%), abdominal distension (37\%), tenderness (31\%) and abdominal mass (29\%). In pediatric patients, abdominal pseudocysts are mostly presented with the symptoms caused by the elevated intracranial pressure; on the other hand, adult patients are usually presented with abdominal symptoms. There are also cases presented with both symptoms, as ours $[2,8]$.
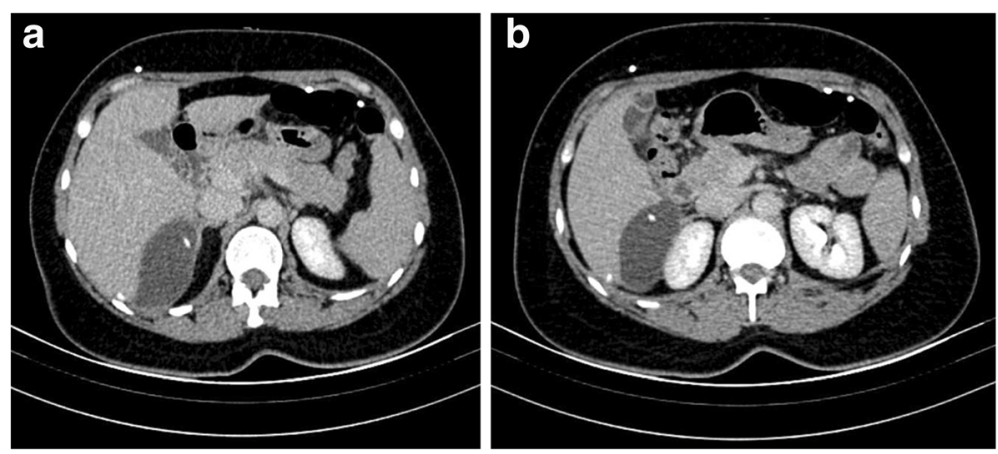

Fig. 2 a In CT scan, subcapsuler $77 \times 47 \times 51 \mathrm{~mm}$ sized cystic mass and abdominal shunt catheter inside. b Folllowing axial section 


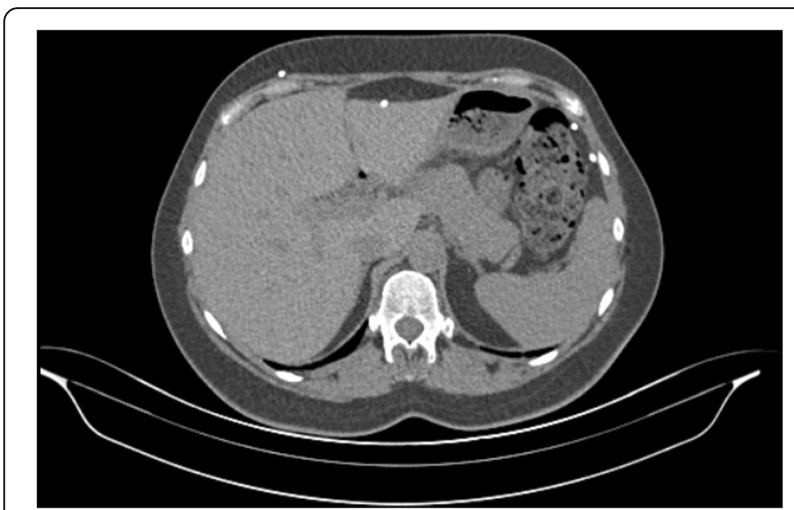

Fig. 3 Control abdominal CT in post-op 8th day. No visible cyst or residue

Main pathologies in differential diagnosis with abdominal pseudocysts are mesenteric or omental cysts, duplication cysts, Iymphocele, cystic teratoma, cystic lymphangioma, pancreatic pseudocyts, abscess and bilomas. It is suggested that abdominal USG and radiography are sufficient for diagnosis, but to determine the exact location, size of the cyst, and the location of the shunt catheter; also to exclude other acute abdominal syndrome reasons, abdominal CT is reported as more valuable $[2,4,6,8]$. Typically, on extrahepatic pseudocyst cases, CT scan reveals a parenchyma free capsule formation with smooth margin extending out from the liver and isodense cyst content with CSF $[6,8,9]$. Cytological examination of cyst ingredient is essential for the final diagnosis.

Treatment options for abdominal pseudocysts are still on debate. General approach is, the removal of the catheter (with or without the removal of the cyst) and sending the catheter to a different quadrant. Aspiration of pseudocyst, laparoscopic cyst excision and laparoscopic shunt installation are a few other suggested treatment modalities [6]. In literature, it is seen that laparoscopy procedures are favored in the recent years [10]. In the presence of an infection, it is suggested that implanting an external ventricular drain and installing a new shunt after appropriate antibiotherapy and seeing CSF is sterile $[2,4,8]$. In our cases we saw that, sending the catheter to a different quadrant, without excision of the pseudocysts, is sufficient. In follow-ups, we observed that the pseudocysts regressed spontaneously after the catheter removal in both of the patients. No recurrence were observed. When we examine closely with laparoscope, as in our first case, we encountered no adhesion between catheter and cyst wall during the removal.

In the first case that was performed laparoscopically, after removal of the shunt catheter, the cyst content was drained spontaneously. During the dissection of the cyst, because of the adhesions, we considered the possibility of liver contusion and decided to leave the cyst. For this reason in the second case, we only removed and replaced the shunt catheter and it was sufficient for the regression of the cyst. When it is certain that the pseudocyst etiology is dependant to the shunt, intra abdominal intervention is not always necessary (laparoscopic or not). Diverting the distal tip of the shunt to a different intra abdominal region is seen to be enough. In cases with persisting distal catheter dysfunction, ventriculoatrial shunt should also be considered.

Although it is rare, VP shunt-induced intraabdominal CSF pseudocysts may occur in every shunt patient. When a VP shunt patient admit us with non-specific abdominal symptoms, the possibility of this complication should always be kept in mind. In the treatment of this complication, it is shown that repositioning the catheter is sufficient for cyst regression. However, it is vital that observing and discussing more cases are essential for truly understanding this complication. Furthermore, the evaluation of shunt patients with every abdominal complication is important in terms of understanding the possible factors in etiology and overcoming the difficulties in clinical and surgical management of VP shunt patients with abdominal complications.

\section{Abbreviations \\ CSF: Cerebrso Spinal Fluid; CT: Computer Tomography; USG: Ultrasonography; VP: Ventriculoperitoneal}

\section{Acknowledgements}

Not applicable.

\section{Funding}

No funding was received.

\section{Availability of data and materials}

Data sharing not applicable to this article as no datasets were generated or analysed during the current study.

\section{Authors' contributions}

GC Major contributor in writing the manuscript. Evaluated the patient, carried out the literature review. EE Major contributor in planning study conception and design. Revised the manuscript. SB Attended the operation. Helped with study conception and design. SCU Attended the operation. Revised the manuscript. YO Attended the operation. Collected data and carried out the follow-up. OMC Helped to draft the manuscript. All authors read and approved the final manuscript.

Ethics approval and consent to participate Ethics approval has obtained from local ethics committee. (Bakirkoy Research and Training Hospital for Neurology, Neurosurgery and Psychiatry, Department of Neurosurgery).

\section{Consent for publication}

Informed written consents have been obtained from both patients, for publication of this case report.

\section{Competing interests}

The authors declare that they have no competing interests.

\section{Author details}

${ }^{1}$ Bakirkoy Research and Training Hospital for Neurology, Neurosurgery and Psychiatry, Department of Neurosurgery, 34147 Bakırkoy/lstanbul, Turkey. ${ }^{2}$ Kanuni Sultan Suleyman Research and Training Hospital, Department of Neurosurgery, Istanbul, Turkey. ${ }^{3}$ Kanuni Sultan Suleyman Research and Training Hospital, Department of General Surgery, Istanbul, Turkey. 
Received: 16 March 2017 Accepted: 31 October 2017

Published online: 08 December 2017

\section{References}

1. Harsh GR 3rd. Peritoneal shunt for hydrocephalus, utilizing the fimbria of the fallopian tube for entrance to the peritoneal cavity. I Neurosurg. 1954;11:284-94

2. Dabdoub CB, Fontoura EA, Santos EA, Romero PC, Diniz CA. Hepatic cerebrospinal fluid pseudocyst: a rare complication of ventriculoperitoneal shunt. Surg Neurol Int. 2013;4:162.

3. Roitberg BZ, Tomita T, McLone DG. Abdominal cerebrospinal fluid pseudocyst: a complication of ventriculoperitoneal shunt in children. Pediatr Neurosurg. 1998:29:267-73.

4. Salomao JF, Leibinger RD. Abdominal pseudocysts complicating CSF shunting in infants and children. Report of 18 cases. Pediatr Neurosurg. 1999;31:274-8

5. Rainov N, Schobess A, Heidecke V, Burkert W. Abdominal CSF pseudocysts in patients with ventriculo-peritoneal shunts. Report of fourteen cases and review of the literature. Acta Neurochir. 1994;127:73-8.

6. Kaplan M, Ozel SK, Akgun B, Kazez A, Kaplan S. Hepatic pseudocyst as a result of ventriculoperitoneal shunts: case report and review of the literature. Pediatr Neurosurg. 2007;43:501-3.

7. Wang F, Miller JH. Cerebrospinal fluid pseudocyst presenting as a hepatic mass: a complication of ventriculoperitoneal shunt. Pediat Radiol. 1989;19:326-7.

8. Verma A, Mohan S, Gupta A. Ventriculo-peritoneal shunts can cause liver injury, juxta and intrahepatic pseudocysts: imaging findings and review of literature. Clin Neurol Neurosurg. 2012;114:389-91.

9. Koçak A, Baysal T, Rüştü Çaylı S, Ateş Ö, Önal Ç. An unusual complication of ventriculo-peritoneal shunt: cerebrospinal fluid cyst in liver. Eur J Radiol Extra. 2004;51:21-4.

10. Oh A, Wildbrett P, Golub R, Yu LM, Goodrich J, Lee T. Laparoscopic repositioning of a ventriculo-peritoneal catheter tip for a sterile abdominal cerebrospinal fluid (CSF) pseudocyst. Surg Endosc. 2001;15:518.

\section{Submit your next manuscript to BioMed Central and we will help you at every step:}

- We accept pre-submission inquiries

- Our selector tool helps you to find the most relevant journal

- We provide round the clock customer support

- Convenient online submission

- Thorough peer review

- Inclusion in PubMed and all major indexing services

- Maximum visibility for your research

Submit your manuscript at www.biomedcentral.com/submit 